\title{
Practice of Coronavirus Disease-19 Prevention Methods and Associated Factors in Three Zones of Southwest Ethiopia: Community based cross- sectional study
}

Wondimagegn Wondimu ( $\square$ wonde1983.ww@gmail.com )

Mizan Tepi University https://orcid.org/0000-0003-4438-6542

Amare Genetu Ejigu

Mizan Tepi University

Mengistu Ayenew Mekonen

Mizan Tepi University

Angesom Weldu

Mizan Tepi University

Wondwossen Niguse Asmare

Mizan Tepi University

Mesfin Geremew

Mizan Tepi University

Gizachew Ayele Manaye

Mizan Tepi University

Ashenafi Asefa Berchedi

Mizan Tepi University

Research Article

Keywords: COVID-19, Southwest Ethiopia, Prevention, Practice

Posted Date: September 29th, 2020

DOl: https://doi.org/10.21203/rs.3.rs-84406/v1

License: (c) (1) This work is licensed under a Creative Commons Attribution 4.0 International License.

Read Full License 


\section{Abstract}

Background Coronavirus disease 19 (COVID-19) is an emerging contagious respiratory infection that brings a big puzzle to global health. In Ethiopia, the number of cases and related deaths are increasing exponentially. Prevention is currently available effective management, and its implementation has not been assessed adequately.

Objective To assess the COVID-19 prevention practices in three zones of Southwest Ethiopia.

Methods A community-based cross-sectional study was conducted in the Bench Sheko, Kafa, and West Omo zones. A multistage sampling technique was employed to select 845 study participants. The data collection tool was adapted from the WHO resources and related literature. SPSS version 20 was used to analyze the data. Participants who scored at least a mean score of practice questions were categorized as having good practice. Binary logistic regression was fitted to identify factors associated with the practice.

Results In this study, 803 participants participated. About two-thirds (64.7\%) of the respondents had a history of going to crowded places, while only $30.3 \%$ of the participants had a history of wearing a mask when leaving home. Two-thirds of the respondents had a history of maintaining their distance at 2 meters $(64.4 \%)$ and washing their hands with soap and water or using alcohol-based hand sanitizers (64.8\%). Generally, less than two-thirds (59.4\%) of study participants had a good practice of COVID-19 prevention methods. Urban residence, good knowledge, positive attitude, intention to seek care, and perceived mortality were positively associated with good practice.

Conclusion The proportion of individuals who had good COVID-19 prevention practices was inadequate. For such highly infectious diseases, prevention should be the priority intervention, and improving its implementation needs further effort. Community-based interventions such as risk communication and mass education should center on scaling up community knowledge and practice by prioritizing vulnerable groups such as rural residents.

\section{Introduction}

Coronavirus disease 19 (COVID-19) is an emerging contagious respiratory infection that brings a large puzzle to global health and has become an international concern (1). It is challenging the health system of the world, and surprisingly, countries with strong health systems are not spared $(2,3)$. In addition to its health impact, it is leading to economic, political, and social crises (4-6).

Since its emergence, the disease has reached 216 countries/territories, infected more than 25 million people, and took 848,255 lives globally as of September 1, 2020 (7,8). In Ethiopia, the disease was first reported on March 13, 2020 (9). Following this, the government of Ethiopia took different measures, such as isolating international passengers, arranging quarantine centers in different sites to follow the suspects, closure of universities and schools, mass disinfection, complete transport lockdown, and the 
release of prisoners (10). As per the Ethiopian Public Health Institute (EPHI) report of August 26, 2020, the total number of cases and deaths were 45,221 and 725 , respectively (11).

As occurred in high-income countries during the emergence of the outbreak, currently, in Ethiopia, the number of cases and related deaths are increasing exponentially compared to those reported before a few months, which is suggestive of community transmission. $(10,12)$.

Currently, the disease has no cure, and prevention is the only available effective weapon to control it. The recommended methods to prevent the pandemic of COVID-19 include regular and thorough cleaning of hands with an alcohol-based hand rub or washing them with soap and clean water, maintaining a physical distance of at least 2 meters, avoiding going to crowded places, and wearing a facemask (13).

Ethiopia is among the countries with a weak health system where the health professional to population ratio is only 0.96 per 1000 populations. This is much lower than the World Health Organization recommended standards (4.45 per 1000 populations) to meet the sustainable development goal health targets $(14,15)$. This implies that if our globe becomes lucky and obtains effective treatment for COVID19, Ethiopia will still be far away from providing treatment for those who will be in need. As a result, maintaining the recommended prevention methods in the country is the first available option to control the disease.

The practice of available prevention methods for COVID-19 in the community should be assessed to design appropriate interventions that can reduce community transmission. However, there is a lack of community-based evidence that discovered how the community is preventing the pandemic of COVID-19 in Ethiopia. Therefore, this study aimed to assess the community practice of COVID-19 prevention methods and associated factors in three zones of Southwest Ethiopia.

\section{Methods And Materials}

\section{Study Design, Setting and period}

A community-based cross-sectional study was conducted in the Bench-Sheko, Kafa, and West Omo zones from May 1 to 31, 2020. These three zones are found at $585 \mathrm{~km}, 460 \mathrm{~km}$ and $705 \mathrm{~km}$ from Addis Ababa, Capital of Ethiopia, respectively, to the southwest direction. The Bench-Sheko zone is administratively divided into six woredas (districts) and two town administrations. The Kafa zone is also divided into eleven woredas and two town administrations. Likewise, the West-Omo Zone has seven woredas. The main agro-ecology of these three zones includes dega (cool and humid high lands, which account for $56.7 \%$ of the land size), kolla (warm, semi-arid lowlands, which account for $28 \%$ of the land size) and weinadega (temperate, cool and sub-humid high lands, which account for 15.3\%). Their annual mean temperature ranges from $15.1^{\circ} \mathrm{C}$ to $27^{\circ} \mathrm{C}$, and the annual mean rainfall ranges between $400 \mathrm{~mm}$ and 2000 $\mathrm{mm}$. In these zones, there are 7 hospitals, 97 health centres and 565 health posts that provide health services for residents. According to the population projection of Ethiopia figured for 2014 to 2017, the Bench-Maji zone (the former collective name for Bench Sheko Zone and West Omo Zone before their 
disunion) had a total population of 847,168 (417,751 males and 429,417 females). Similarly, the Kafa Zone had a population size of $1,102,278$ (541,682 males and 560,596 females) (16).

\section{Population and Sampling Techniques}

The adult population who were 18 years old and above were included in this study. Individuals who were unable to respond due to different medical problems were excluded. The sample size was determined using a single population proportion formula [], where " $n$ " stands for sample size, " $z_{\alpha / 2}$ " stands for the reliability coefficient of standard error at the $5 \%$ level of significance, which equals 1.96 , "p" stands for the proportion of good COVID-19 prevention practice, which was considered as $50 \%$ (since there was no previous study at comparable area), and "d" stands for the level of standard error tolerated, taken as $5 \%$. The calculated sample was 384.16. After using the design effect of 2 and adding a non-response rate of $10 \%$, the final sample size became 845 .

A multistage sampling technique was employed to select the study participants. First, ten woredas and town administrations (three from Bench Sheko, three from West Omo and four from Kafa) were selected randomly and included in the study. Likewise, thirty percent of Kebeles (smallest administrative units) were selected from each of the selected woredas and town administrations. Then, the calculated samples were allocated to each of the selected Kebeles proportional to the size of households in the Kebeles. Finally, the households were selected using a systematic random sampling technique, and from each of the selected households, one eligible participant was selected by the lottery method.

\section{Data Collection Technique and Data Quality Control}

A pretested interviewer-administered structured questionnaire (see Additional file 1) adapted from WHO recommendations regarding COVID-19 prevention practices and a previous similar study was used to collect the data $(13,17,18)$. The tool includes the sociodemographic characteristics of the study participants (age, sex, religion, residence, ethnicity, marital status, occupational status, educational status, family size), knowledge questions about COVID-19 (which includes about clinical symptoms, transmission, risk factors, treatment, and vulnerable groups), attitude questions (mainly about the success of the control at an individual and national level, the effectiveness of local treatments such as hot drinks, and the probability of the occurrence of the virus in the locality), practice questions (about risky and positive behaviors practiced recently) and others. The questionnaire was prepared in English and translated to the local language (Amharic) by a language expert. It was also back-translated to English by another expert to ensure its consistency. The Amharic version questionnaire was used to collect the data. To assure the quality of the data, two days of training was given before data collection for data collectors and supervisors about the objective of the study, techniques of data collection, different ethical issues, and care to be taken regarding COVID-19 during data collection. A pretest was performed on $10 \%$ of the total sample size in the comparable Kebeles that were not included in the actual study, and some modifications were added to the tool. Data were collected by thirty diploma nurses, and 
the overall collection process was supervised by ten BSc nurses. The supervisors checked each filled questionnaire for completeness during the data collection.

\section{Variables and measurement}

The outcome variable of this study was the practice of COVID-19 prevention methods. The independent variables were sociodemographic characteristics (age, sex, residence, ethnicity, marital status, occupational status, educational status, family size), knowledge about COVID-19, attitude toward COVID19 prevention methods, intention to seek care and perceived mortality.

The participants were asked 14 knowledge questions, 9 attitude questions, and 8 practice questions. Participants who scored at least the mean score of the above questions for each category were considered to have good knowledge, a positive attitude, and good practice.

\section{Data entry, processing and analysis}

Data were entered into Epi data manager version 4.0.2.101 and exported to Statistical Packages for Social Science (SPSS) version 20 for analysis. Data were cleaned to check for outliers and miscoded variables. Furthermore, negatively worded items were reverse scored. Data are presented as tables and proportions (percentages). Binary logistic regression was used to assess the association between the independent variables and an outcome variable. The odds ratio (OR) with its respective $95 \%$ confidence interval $(\mathrm{Cl})$ and the p-value were used to measure the strength of the association. In the bivariable analysis, variables with $p$-values $<0.25$ were considered candidates for multivariable analysis. The final significance was declared at a $\mathrm{p}$-value $<0.05$.

\section{Result}

\section{Characteristics of the study participants}

In this study, out of the 845 total samples, 803 fully participated, resulting in a response rate of $95 \%$. Among the total study participants, more than half were males (57.8\%), Orthodox Tewahido religion followers $(56.4 \%)$, and found in the age category of $18-30$ years old $(52.8 \%)$. Similarly, approximately onethird of the respondents had Kafa ethnicity (31.1\%) and single marital status (32.1\%). Furthermore, approximately two-thirds of the study participants had urban residence $(67.7 \%)$, good knowledge about COVID-19 (64.6\%), and positive attitude toward COVID-19 (66\%). [Table 1]

Table 1- The characteristics of the study participants in the Bench Sheko, Kafa and West Omo zones, South West Ethiopia, 2020 


\begin{tabular}{|c|c|c|c|}
\hline Variable & Category & $\begin{array}{l}\text { Frequency } \\
\text { (803) }\end{array}$ & $\begin{array}{l}\text { Percentage } \\
(\%)\end{array}$ \\
\hline \multirow[t]{2}{*}{ Sex } & Male & 464 & 57.8 \\
\hline & Female & 339 & 42.2 \\
\hline \multirow[t]{2}{*}{ Residence } & Urban & 544 & 67.7 \\
\hline & Rural & 259 & 32.3 \\
\hline \multirow[t]{3}{*}{ Age } & $18-30$ & 423 & 52.8 \\
\hline & $31-40$ & 223 & 27.8 \\
\hline & $>40$ & 156 & 19.4 \\
\hline \multirow[t]{6}{*}{ Ethnicity } & Bench & 133 & 16.6 \\
\hline & Sheka & 102 & 12.7 \\
\hline & Amhara & 112 & 13.9 \\
\hline & Kafa & 150 & 31.1 \\
\hline & Oromo & 94 & 11.7 \\
\hline & Others $^{\mathrm{a}}$ & 112 & 13.9 \\
\hline \multirow[t]{4}{*}{ Marital status } & Single & 258 & 32.1 \\
\hline & Married & 435 & 54.2 \\
\hline & Divorced/widowed & 74 & 9.2 \\
\hline & Separated & 36 & 4.5 \\
\hline \multirow[t]{7}{*}{ Occupational status } & Unemployed & 93 & 11.6 \\
\hline & Farmer & 161 & 20.0 \\
\hline & Daily laborer & 96 & 12.0 \\
\hline & Merchant & 135 & 16.8 \\
\hline & Government employee & 141 & 17.6 \\
\hline & Private business & 113 & 14.1 \\
\hline & Students & 64 & 8.0 \\
\hline \multirow[t]{5}{*}{ Educational status } & Cannot read and write & 155 & 18.3 \\
\hline & Can read and write & 149 & 18.6 \\
\hline & Primary (grade 1-8) & 176 & 21.9 \\
\hline & $\begin{array}{l}\text { Secondary or } \\
\text { preparatory }\end{array}$ & 142 & 17.7 \\
\hline & Diploma and above & 181 & 22.5 \\
\hline \multirow[t]{4}{*}{ Religion } & Orthodox Tewahido & 453 & 56.4 \\
\hline & Muslim & 99 & 12.3 \\
\hline & Protestant & 207 & 25.8 \\
\hline & Otherb $^{\mathrm{b}}$ & 44 & 5.5 \\
\hline \multirow[t]{3}{*}{ Family size } & One to three & 390 & 48.6 \\
\hline & Four to six & 341 & 42.5 \\
\hline & Seven and more & 72 & 9 \\
\hline \multirow{2}{*}{$\begin{array}{lll}\text { Perceived } & \text { mortality } & \text { of } \\
\text { COVID-19 }\end{array}$} & Yes & 347 & 43.2 \\
\hline & No & & \\
\hline \multirow[t]{2}{*}{ Knowledge } & Good & 519 & 64.6 \\
\hline & Poor & & \\
\hline \multirow[t]{2}{*}{ Attitude } & Positive & 530 & 66 \\
\hline & Negative & & \\
\hline \multirow[t]{2}{*}{ Intend to seek care } & Have intention & 458 & 57 \\
\hline & No intention & 345 & 43 \\
\hline
\end{tabular}


${ }^{\mathrm{a}}$ Menit and Dizu; ${ }^{\mathrm{b}}$ Catholic and traditional belief

\section{Practice of COVID-19 prevention methods among study participants}

Approximately two-thirds (64.7\%) of the respondents had a history of going to crowded places. However, only approximately one-third (30.3\%) of the total study participants had a history of wearing a mask when leaving home. The majority $(68.1 \%)$ of the study participants had a history of covering their mouth and nose when coughing and sneezing. Two-thirds of the respondents had a history of maintaining their distance at 2 meters (64.4\%) and washing their hands with soap and water or using alcohol-based hand sanitizers $(64.8 \%)$. However, a significant proportion $(45.6 \%)$ of them had a history of eating raw/uncooked foods. Generally, less than two-thirds (59.4\%) of study subjects had a good practice of COVID-19 prevention methods. [Table 2]

Table 2- Practice of COVID-19 prevention methods among study participants in Bench Sheko, Kafa and West Omo zones, South West Ethiopia, 2020 


\begin{tabular}{|c|c|c|}
\hline Question /variables/ & $\begin{array}{l}\text { Response } \\
\text { /Categories/ }\end{array}$ & $\mathrm{N}(\%)$ \\
\hline \multirow[t]{2}{*}{ Recent history of going to any crowded place } & Yes & $\begin{array}{l}518 \\
(64.7)\end{array}$ \\
\hline & No & $\begin{array}{l}283 \\
(35.3)\end{array}$ \\
\hline \multirow[t]{2}{*}{ Recent history of wearing a mask when leaving home } & Yes & $\begin{array}{l}243 \\
(30.3)\end{array}$ \\
\hline & No & $\begin{array}{l}558 \\
(69.7)\end{array}$ \\
\hline \multirow[t]{2}{*}{$\begin{array}{l}\text { Recent history of washing hands with soap and water frequently or } \\
\text { using alcohol-based hand sanitizers }\end{array}$} & Yes & $\begin{array}{l}520 \\
(64.8)\end{array}$ \\
\hline & No & $\begin{array}{l}283 \\
(35.2)\end{array}$ \\
\hline \multirow[t]{2}{*}{ A recent habit of touching eye, nose, and mouth } & Yes & $\begin{array}{l}503 \\
(62.6)\end{array}$ \\
\hline & No & $\begin{array}{l}300 \\
(37.4)\end{array}$ \\
\hline \multirow[t]{2}{*}{$\begin{array}{l}\text { Recent history of covering mouth and nose when coughing and } \\
\text { sneezing }\end{array}$} & Yes & $\begin{array}{l}547 \\
(68.1)\end{array}$ \\
\hline & No & $\begin{array}{l}256 \\
(31.9)\end{array}$ \\
\hline \multirow[t]{2}{*}{ Recent history of maintaining physical distance at 2 meters } & Yes & $\begin{array}{l}515 \\
(64.4)\end{array}$ \\
\hline & No & $\begin{array}{l}285 \\
(35.6)\end{array}$ \\
\hline \multirow[t]{2}{*}{ Recent history of eating raw/uncooked foods } & Yes & $\begin{array}{l}366 \\
(45.6)\end{array}$ \\
\hline & No & $\begin{array}{l}437 \\
(54.4)\end{array}$ \\
\hline \multirow[t]{2}{*}{ Recent history of shaking hands of others } & Yes & $\begin{array}{l}308 \\
(38.4)\end{array}$ \\
\hline & No & $\begin{array}{l}495 \\
(61.6)\end{array}$ \\
\hline \multirow[t]{2}{*}{ Overall practice } & Good & $\begin{array}{l}477 \\
(59.4)\end{array}$ \\
\hline & Poor & $\begin{array}{l}326 \\
(40.6)\end{array}$ \\
\hline
\end{tabular}




\section{Factors associated with prevention practices of COVID-19}

In bivariable logistic regression, residence, educational status, occupation, marital status, family size, knowledge, attitude, intention to seek care and perceived mortality were statistically significant at pvalues less than 0.25 . After controlling for confounders, in multivariable logistic regression, residence, knowledge status, attitude status, intention to seek care, and perceived mortality were significantly associated with the COVID-19 prevention practices of the participants at a p-value less than 0.05 .

Urban residents had more than two $(A O R=2.34)$ times higher odds of good practice compared to rural residents. Similarly, participants who were from the highest family size (more than six) had three $(A O R=2.95)$ times higher odds of practice than those from the lowest (one to three) family size. Good knowledge status ( $A O R=1.74)$ and positive attitude ( $A O R=1.86)$ had a positive influence on COVID-19 prevention practices compared to their counterparts (poor knowledge and negative attitude, respectively). Furthermore, respondents who had the intention to seek care for COVID-19 symptoms had $73 \%$ (AOR=1.73) increased odds of good practice than those who had no intention. Lastly, individuals who had a perception of COVID-19-related death had double $(A O R=2.20)$ odds of good practice than those who had no such perception. [Table 3]

Table 3- Factors associated with prevention practices of COVID-19 among the study participants in Bench Sheko, Kafa and West Omo zones, South West Ethiopia, 2020 


\begin{tabular}{|c|c|c|c|c|c|c|}
\hline \multirow[t]{2}{*}{ able } & \multirow[t]{2}{*}{ Category } & \multicolumn{2}{|c|}{ Practice } & \multirow[t]{2}{*}{ COR (95\% CI) } & \multirow{2}{*}{ AOR $\quad(95 \%$} & \multirow{2}{*}{$\begin{array}{l}\mathrm{P}- \\
\text { value }\end{array}$} \\
\hline & & No & Yes & & & \\
\hline \multirow[t]{2}{*}{ dence } & Urban & 146 & 398 & $\begin{array}{l}6.21 \quad(4.49, \\
8.60)\end{array}$ & $\begin{array}{ll}2.34 & (1.39, \\
3.94) & \end{array}$ & $0.001 *$ \\
\hline & Rural & 180 & 79 & 1 & 1 & \\
\hline \multirow[t]{5}{*}{$\begin{array}{l}\text { cational } \\
\text { us }\end{array}$} & $\begin{array}{l}\text { Cannot read and } \\
\text { write }\end{array}$ & 101 & 54 & 1 & 1 & \\
\hline & Can read and write & 60 & 89 & $\begin{array}{l}2.77 \\
4.42)\end{array}$ & $\begin{array}{ll}1.04 & (0.58, \\
1.87) & \end{array}$ & 0.904 \\
\hline & Primary & 71 & 105 & $\begin{array}{l}2.77 \quad(1.77 \\
4.33)\end{array}$ & $\begin{array}{|ll|}1.12 & (0.62, \\
2.01) & \end{array}$ & 0.707 \\
\hline & Secondary & 56 & 86 & $\begin{array}{l}2.87 \\
4.60)\end{array}$ & $\begin{array}{ll}1.08 & (0.58, \\
2.01) & \end{array}$ & 0.813 \\
\hline & Diploma and above & 38 & 143 & $\begin{array}{l}7.04 \quad(4.33 \\
11.45)\end{array}$ & $\begin{array}{|ll|}1.65 & (0.82, \\
3.33) & \\
\end{array}$ & 0.160 \\
\hline \multirow[t]{7}{*}{ apation } & Unemployed & 42 & 51 & 1 & 1 & \\
\hline & Farmer & 121 & 40 & $\begin{array}{l}0.27 \quad(0.16 \\
0.47)\end{array}$ & $\begin{array}{ll}0.68 & (0.35, \\
1.33) & \end{array}$ & 0.264 \\
\hline & Daily labor & 30 & 66 & $\begin{array}{l}1.81 \quad(1.00, \\
3.28)\end{array}$ & $\begin{array}{ll}1.72 & (0.84, \\
3.51) & \end{array}$ & 0.136 \\
\hline & Merchant & 38 & 97 & $\begin{array}{l}2.10 \quad(1.21 \\
3.66)\end{array}$ & $\begin{array}{ll}1.54 & (0.81 \\
2.93) & \end{array}$ & 0.191 \\
\hline & $\begin{array}{l}\text { Government } \\
\text { employee }\end{array}$ & 31 & 110 & $\begin{array}{l}2.92 \quad(1.65 \\
5.17)\end{array}$ & $\begin{array}{|ll|}1.64 & (0.78, \\
3.48) & \end{array}$ & 0.194 \\
\hline & Private business & 44 & 69 & $\begin{array}{l}1.29 \quad(0.74 \\
2.25)\end{array}$ & $\begin{array}{|ll|}0.99 & (0.51, \\
1.93) & \\
\end{array}$ & 0.976 \\
\hline & Students & 20 & 44 & $\begin{array}{l}1.81(0.93 \\
3.53)\end{array}$ & $\begin{array}{ll}1.50 & (0.69, \\
3.24) & \end{array}$ & 0.303 \\
\hline ital status & Single & 94 & 164 & 1 & 1 & \\
\hline
\end{tabular}




\begin{tabular}{|c|c|c|c|c|c|c|c|c|}
\hline & Married & 190 & 245 & $\begin{array}{l}0.74 \\
1.01)\end{array}$ & $(0.54$ & $\begin{array}{l}0.70 \\
1.05)\end{array}$ & $(0.46$ & 0.081 \\
\hline & $\begin{array}{l}\text { Divorced/ } \\
\text { Widowed }\end{array}$ & 30 & 44 & $\begin{array}{l}0.84 \\
1.43)\end{array}$ & $(0.50$ & $\begin{array}{l}0.93 \\
1.77)\end{array}$ & (0.49) & 0.832 \\
\hline & Separated & 12 & 24 & $\begin{array}{l}1.15 \\
2.40)\end{array}$ & $(0.55$ & $\begin{array}{l}0.94 \\
2.17)\end{array}$ & $(0.40$ & 0.877 \\
\hline \multirow[t]{3}{*}{ ily size } & One to three & 166 & 224 & 1 & & 1 & & \\
\hline & Four to six & 137 & 204 & $\begin{array}{l}1.10 \\
1.48)\end{array}$ & $(0.82$ & $\begin{array}{l}1.37 \\
1.99)\end{array}$ & $(0.94$ & 0.098 \\
\hline & More than six & 23 & 49 & $\begin{array}{l}1.58 \\
2.69)\end{array}$ & (0.93, & $\begin{array}{l}2.95 \\
5.57)\end{array}$ & (1.56) & $0.001 *$ \\
\hline \multirow{2}{*}{$\begin{array}{l}\text { wledge } \\
\text { is }\end{array}$} & Poor & 189 & 95 & 1 & & 1 & & \\
\hline & Good & 137 & 382 & $\begin{array}{l}5.55 \\
7.60)\end{array}$ & (4.05) & $\begin{array}{l}1.74 \\
2.77)\end{array}$ & (1.10, & 0.019* \\
\hline \multirow[t]{2}{*}{ ude status } & Negative & 167 & 106 & 1 & & 1 & & \\
\hline & Positive & 159 & 371 & $\begin{array}{l}3.68 \\
4.99)\end{array}$ & $(2.71$ & $\begin{array}{l}1.86 \\
2.73)\end{array}$ & & $0.001 *$ \\
\hline \multirow{2}{*}{ nd to seek } & No intention & 210 & 135 & 1 & & 1 & & \\
\hline & Have intention & 116 & 342 & $\begin{array}{l}4.59 \\
6.20)\end{array}$ & (3.39, & $\begin{array}{l}1.73 \\
2.63)\end{array}$ & $(1.13$ & $0.011^{*}$ \\
\hline \multirow{2}{*}{$\begin{array}{l}\text { :eived } \\
\text { tality }\end{array}$} & Yes & 171 & 176 & 1 & & 1 & & \\
\hline & No & 155 & 301 & $\begin{array}{l}1.89 \\
2.51)\end{array}$ & $(1.42$ & $\begin{array}{l}2.20 \\
3.08)\end{array}$ & $(1.50$ & $0.000 *$ \\
\hline
\end{tabular}

* statistically significant at p-value <0.05; AOR-Adjusted Odds Ratio; CI- Confidence Interval; COR-Crude Odds Ratio

\section{Discussion}

This study revealed that approximately two-thirds (64.7\%) of the respondents had a history of going to a crowded place, which is comparable to the finding of the study conducted at Jimma University Medical Center (JUMC) (19). However, it is very high compared to the study conducted in China (17), where only 
$3.6 \%$ visited crowded places. The discrepancy might be due to the difference in socio-economic and demographic characteristics between the two countries. Since COVID-19 has a higher potential for person-to-person transmission, exposure to crowded places is risky behavior and should be discouraged.

One of the important findings in this study is that only one-third $(30.3 \%)$ of the study participants had a history of wearing a protective mask when leaving home. This is very low compared to the finding from China (17), and it is also contrary to the WHO recommendations (19). This figure is very frustrating in the case of Ethiopia, where the community transmission of COVID-19 is more likely $(10,12)$. An additional finding that magnifies the problem of COVID-19 prevention practice is that a significant proportion (35.6\%) of people did not maintain appropriate physical distance. As a result, efforts should be made to encourage the public to use a protective mask and maintain appropriate physical distance as per the WHO recommendations.

Our findings show that only three of five participants had good COVID-19 prevention practices. This is very low compared to the Iranian finding (20), and the discrepancy might be attributable to the differences in socio-economic statuses and attention given by the community. This finding is highly public health important for Ethiopia, which was grouped as among African countries vulnerable to COVID19 (21). This is because the provision of important health services to COVID-19 patients requires expensive resources, and in Ethiopia, the majority of the health services are substandard mainly due to resource scarcity $(14,15)$. For instance, Ethiopia had 557 mechanical ventilators and 570 intensive care unit (ICU) beds for a population of 110 million (10). Thus, a major emphasis on prevention is mandatory, and sustainable intervention should be made to increase its implementation.

In this study, participants from urban residents had more than two times higher odds of practice than those from rural residents. This might be because urban residents had better access to COVID-19-related information and resources needed to prevent COVID-19, such as alcohol-based sanitizers, soap, water, and protective masks. In addition, the rural community may not obtain adequate information regarding COVID-19 due to limited access to phone and/or internet, which is common for the rural community of Ethiopia (10).

Higher family size (more than six) had three times higher odds of practice compared to those with lower family size. Members of an increased family size probably bring information related to COVID-19 prevention from different sources and discuss it, which could enable them to change it into practice.

Participants with good knowledge status about COVID-19 had more than one and a half times higher odds of practice compared to those with poor knowledge status. This is also supported by the previous finding where knowledge and practice were associated with direct proportionality (17). Most of the time, it is straightforward that having knowledge enables people to practice what they know. People who have good knowledge about the disease, its severity, transmission methods, and prevention methods can value their lives and take appropriate measures. 
Likewise, individuals with a positive attitude regarding the success of COVID-19 prevention methods had $86 \%$ increased odds of good practice compared to those with a negative attitude. It is obvious that when people rely on the success of prevention methods, their interest in applying these methods will be high. Therefore, the information should be disseminated continuously to increase the trust of the community in prevention methods and to avoid their concentration on fake news that discourages preventive behaviors.

In our study, respondents who perceived that COVID-19 can lead to death had two times higher odds of good practice of preventive measures against COVID-19 compared to their counterparts. People in the world prefer to live long on the earth and invest to alleviate the risk of death as much as possible. Educating the community about the severe outcome of the COVID-19 could benefit them to have appropriate prevention behaviors. However, this should be done in a manner that will not bring an exaggerated panic to the community.

\section{Limitation}

This is the self-reported practice of COVID-19 prevention methods, and there may be the probability of social desirability bias.

\section{Conclusion}

The proportion of individuals who had good COVID-19 prevention practices was inadequate in our study area. Moreover, the practice of wearing a protective mask and maintaining recommended physical distance is very low, and these all need immediate interventions. It was also demonstrated that urban residents had good practice compared to rural residents. This gap should be addressed by educating rural dwellers and availing important inputs for COVID-19 prevention methods, keeping in mind that $79 \%$ of Ethiopians are living in rural areas with weak transportation and communication links (10). The respondents had moderate knowledge and attitudes about COVID-19, which had a positive influence on good practice. Thus, it is also important to center the interventions on updating the knowledge and attitude of respondents. This can also enhance the community's perceived mortality, which was recognized as a significant predictor of good practice. Overall, such highly infectious disease prevention should be a priority intervention, and the prevention practice of the community in our study area needs further effort.

\section{List Of Abbreviations}

AOR Adjusted Odds Ratio; Cl Confidence Interval; COVID-19 Coronavirus Disease 19; EPHI Ethiopian Public Health Institute; ICU Intensive Care Unit; JUMC Jimma University Medical Center; OR Odds Ratio, SPSS Statistical Package for Social Sciences; WHO World Health Organization

\section{Declarations}

\section{Ethics approval and consent to participate}


The study protocol was approved by the ethical review committee of the health science college of Mizan Tepi University, and the approval letter with reference number HSC/0032/20 was obtained. The study participants were briefed about the purpose of the study, their right to participate or not, and the quitting of participation at any point of time during the data collection. Written informed consent was obtained from each participant. The possible prevention methods of COVID-19 (wearing a protective facemask and keeping at least 2 meters of physical distance) were implemented during data collection. The collected data were kept confidential.

\section{Consent for publication}

Not applicable.

\section{Availability of data and materials}

The datasets used and/or analyzed during the current study are available from the corresponding author on reasonable request.

\section{Competing interests}

The authors declare no conflicts of interest.

\section{Funding}

Not applicable.

\section{Authors' contributions}

Conceptualization: WW, WN, MA, AW. Data curation: WW, MA, AW, AA. Formal analysis: WW, MG, AG, MA, GA, AW. Funding acquisition: None. Methodology: WW, MG, WN, AG, MA, AW, AA. Project administration: WN and MA. Visualization: MG, WN, AG, GA, AW, AA. Writing - original draft: WW, MG, AG, MA, GA, AA. Writing - review \& editing: MG, WN, AG, GA, AW, AA.

\section{Acknowledgments}

The authors would like to acknowledge the supervisors, data collectors, and study participants for their participation in this research and the local government bodies for their support.

\section{Authors' Information (Affiliations)}

1 Department of Public health, College of Medicine and Health Science, Mizan-Tepi University Mizan Aman, Ethiopia

2 Department of Nursing, College of Medicine and Health Science, Mizan-Tepi University Mizan Aman, Ethiopia 
3 Department of Midwifery, College of Medicine and Health Science, Mizan-Tepi University Mizan Aman, Ethiopia, https://orcid.org/0000-0003-3972-9555

4 Department of Medical Laboratory, College of Medicine and Health Science, Mizan-Tepi University Mizan Aman, Ethiopia

\section{References}

1. Lu H, Stratton CW, Tang YW. Outbreak of pneumonia of unknown etiology in Wuhan, China: The mystery and the miracle. J Med Virol. 2020;92:401-2.

2. Austin Price. The lasting impact of the COVID-19 pandemic on our healthcare delivery system I Berkeley News [Internet]. Berkeley, University of Calfornia. 2020 [cited 2020 May 14]. Available from: https://news.berkeley.edu/2020/05/04/the-lasting-impart-of-the-covid-19-pandemic-on-ourhealthcare-delivery-system/

3. Lai C, Wang C, Wang Y, Hsueh S, Ko W, Hssueh P-R. Global epidemiology of coronavirus disease 2019 (COVID-19): disease incidence, daily cumulative index, mortality, and their association with country healthcare resources and economic status. Int J Antimicrob Agents [Internet]. 2020;55. Available from: https://doi.org/10.1016/j.ijantimicag.2020.105946

4. International Labor Organization. COVID-19 and the world of work: Impact and policy responses. 2020;(March):1-15. Available from: http://hdl.voced.edu.au/10707/533608

5. Maor M, Suliteazonu-Kenan R, Chinitz D. When COVID-19, constitutional crisis, and political deadlock meet: the Israeli case from a disproportionate policy perspective. J Policy Soc. 2020;39(3).

6. Oldekop JA, Horner R, Hulme D, Adhikari R, Agarwal B, Alford M, et al. COVID-19 and the case for global development. World Dev [Internet]. 2020;134:1-4. Available from: https://doi.org/10.1016/j.worlddev.2020.105044

7. World Health Organization(WHO). Coronavirus disease (COVID-19) pandemic- Situational Update [Internet]. WHO. 2020 [cited 2020 Jul 31]. Available from:

https://www.who.int/emergencies/diseases/novel-coronavirus-2019

8. Johns Hopkins University (JHU). COVID-19 Dashboard by the Center for Systems Science and Engineering (CSSE) at Johns Hopkins University (JHU) [Internet]. JHU. 2020 [cited 2020 Aug 9]. Available from: https://coronavirus.jhu.edu/map.html

9. World Health Organization (WHO). First Case of COVID-19 Confirmed in Ethiopia [Internet]. WHO. 2020 [cited 2020 Aug 1]. Available from: https://www.afro.who.int/news/first-case-covid-19confirmed-ethiopia

10. Shigute Z, Mebratie AD, Alemu G, Bedi A. Containing the spread of COVID-19 in Ethiopia. J Glob Health. 2020;10(1):1-4.

11. Ethiopian Public Health Institute (EPHI). Status update on COVID19 Ethiopia [Internet]. EPHI. 2020 [cited 2020 Aug 9]. Available from: https://covid19.ephi.gov.et/status-update-on-covid19-ethiopiaaugust-7-2020/ 
12. Biadgilign S, Yigzaw M. COVID-19 in Ethiopia: current situation, missed opportunities, and the risk of health system disruptions. Pan Afr Med J. 2020;35(2):66.

13. World Health Organization(WHO). Coronavirus disease (COVID-19) advice for the public [Internet]. WHO. 2020 [cited 2020 Aug 3]. Available from: https://www.who.int/emergencies/diseases/novelcoronavirus-2019/advice-for-public

14. Haileamlak A. How Can Ethiopia Mitigate the Health Workforce Gap to Meet Universal Health Coverage? Ethiop J f Heal Sci. 2018;28(3):249-50.

15. World Health Organization(WHO). Health Workforce Requirements for Universal Health Coverage and the Sustainable Development Goals. Human Resource for Health Observers Series No. 17 [Internet]. WHO. 2016 [cited 2020 May 23]. Available from: http://www.who.int/hrh/resources/WH\%0AO_GSHRH_DRAFT_05Jan16.pdf?ua=1

16. Federal Democratic Republic of Ethiopia Central Statistical Agency. Population Projection of Ethiopia for All Regions At Wereda Level from 2014 - 2017. 2013;114-5. Available from:

http://www.csa.gov.et/ehioinfo-internal\%3Fdownload\%3D724:population-projection-of-eth

17. Zhong B, Luo W, Li H, Zhang Q, Liu X, Li W, et al. Knowledge, attitudes, and practices towards COVID19 among Chinese residents during the rapid rise period of the COVID-19 outbreak: a quick online cross-sectional survey. Int J Biol Sci. 2020;16(10):1745-52.

18. World Health Organization(WHO). Risk Communication and Community Engagement (RCCE) Action Plan Guidance COVID-19 Preparedness and Response [Internet]. 2020. Available from: https://www.who.int/docs/\%0Adefault-source/coronaviruse/covid19-rcce-guidance-final-brand.pdf

19. Kebede Y, Yitayih Y, Birhanu Z, Mekonen S, Ambelu A. Knowledge, perceptions and preventive practices towards COVID-19 early in the outbreak among Jimma university medical center visitors, Southwest Ethiopia. PLoS One [Internet]. 2020;1-15. Available from: http://dx.doi.org/10.1371/journal.pone.0233744

20. Erfani A, Shahriarirad R, Ranjbar K, Mirahmadizadeh A \& Moghadami M. Knowledge, Attitude and Practice toward the Novel Coronavirus (COVID-19) Outbreak: A Population-Based Survey in Iran. Bull World Health Organ. E-pub: 30 March 2020. doi: http://dx.doi.or.

21. Gilbert M, Pullano G, Pinotti F, Valdano E, Poletto C, Boëlle P, et al. Preparedness and vulnerability of African countries against importations of COVID-19: a modelling study. Lancet. 2020;395:871-7.

\section{Supplementary Files}

This is a list of supplementary files associated with this preprint. Click to download.

- Questionnaire.docx 